\title{
Optimising irrigated agricultural productivity under varying water availability: industry challenges in northern Victoria
}

\author{
$\underline{\text { C. Beverly }}{ }^{\mathrm{a}}$, K. Stott ${ }^{\mathrm{a}}$, J. McInnes ${ }^{\mathrm{a}}$ and C. Thompson ${ }^{\mathrm{b}}$ \\ ${ }^{a}$ Agriculture Research, Agriculture Victoria, Department of Economic Development, Jobs, Transport and \\ Resources, Victoria. \\ ${ }^{b}$ RMCG, Bendigo, Australia. \\ Email: craig.beverly@ecodev.vic.gov.au
}

\begin{abstract}
In an environment of uncertain water allocations, irrigated agriculture in Northern Victoria is being challenged to meet the opportunities of a growing domestic and international market. Historically, increased agricultural demand has relied on access to readily available water and productive land. Under current environmental flow obligations and water caps, access to high- and low-reliability water varies by season and is constrained by sustainable diversion limits (SDLs). Assessing options to increase irrigated agricultural production under varying water allocations required the development of an economic framework to enable an evaluation of the balance between environmental flow obligations, consumptive water-use demands, crop performance and farm profitability.
\end{abstract}

The developed bio-economic model, known as the Water Policy Model (WPM), considers all irrigation districts in northern Victoria and evaluates the economic efficiency implications of specific water allocations and water allocation methods (such as water trading) to ensure that environmental goals are achieved at lowest economic cost. The range of farm activities modelled includes permanent horticulture, summer and winter crops, livestock production, hay production for on-farm use or sale, and maintaining and feeding pasture. The commodities considered are irrigated and dryland pastures, summer and winter grains, pome fruits, grapes, tomatoes, citrus, stone fruits, almonds, olives, dairy cattle, beef cattle and sheep. The total area modelled is $1,601,474$ ha.

The model adopts a non-linear optimisation approach and is capable of assessing: the impact of various trading rules; the relative impacts of improvements in crop yields and water delivery technologies on profitability and water use; the economic impacts of substitution of surface water with groundwater; the impacts of commodity price shocks on water use and enterprise type; and the conditions resulting in the transition between irrigated dairy, mixed cropping and irrigated horticulture. The design of the optimisation model is to maximise total net benefits under various constraints including water availability, farm activity, available irrigated farming area, trading rules, SDLs (surface water and groundwater) and production volume. The model utilises satellite data and water/yield production functions based on farming system models.

Results suggest that farm gate profitability from irrigated agriculture in northern Victoria can be increased from $\$ 2.2 \mathrm{~b}$ to $\$ 3.6 \mathrm{~b}$ assuming the current range of land uses, or $\$ 3.8 \mathrm{~b}$ if available groundwater within SDL settings is $50 \%$ utilised and to $\$ 4.4 \mathrm{~b}$ with access to additional groundwater and adoption of $10 \%$ improvement in water efficiency via genetic improvement, system design and precision water management. Overall, these results imply that achieving maximum profitability for irrigated agriculture industries under future water availability scenarios involves political and economic implications related to land use and access to various sources of water.

The results have been used to inform government and stakeholders of the likely costs in achieving environmental outcomes. Due to the interactive and agile modelling approach developed in this study, enhanced engagement with stakeholders through active participation was achieved. This resulted in improved understanding of complex interactions and informed discussion about the potential trade-offs between meeting environmental flow obligations and maintaining irrigated agricultural profitability in northern Victoria.

Keywords: Bio-economic model, Decision Support System (DSS), irrigated agriculture 
Beverly et al., Optimising irrigated agricultural productivity under varying water availability: industry challenges in northern Victoria

\section{INTRODUCTION}

Water is a finite resource that must be shared among multiple users with often competing economic and environmental objectives. The necessity to analyse the trade-offs between these objectives has led to the development of integrated water management frameworks that estimate the economic consequences of water management. One approach has been to couple separate economic and hydrological models that enable the analysis at fine scale but this approach requires customised software integration (Bharati et al., 2008). Detailed hydrological models are typically computationally complex and the optimisation process to evaluate trade-offs may take weeks to complete. A more efficient approach is the use of integrated bio-economic models that enable the rapid exploration of alternative scenarios at broad scale (Beverly et al., 2016; Warfe and Tisdell, 2016). Importantly, the complexity of such models can be readily altered which is a key consideration if the model and results are to be applied in multiple contexts (Doole, 2015) and/or communicated to diverse stakeholders. As such, integrated bio-economic models offer a way to achieve more informed decision-making through the integration of biophysical and economic data, thereby enabling an assessment of the environmental and economic impacts of agricultural management decisions.

This paper describes the development of a bio-economic spatial optimisation model to assess the profitability of various agricultural sectors within the irrigated region of northern Victoria under a range of water availability conditions whilst meeting Sustainable Diversion Limit (SDL) environmental targets as legislated in the Murray-Darling Basin Plan (Murray-Darling Basin Authority, 2012). The model design integrates knowledge from a range of sources, disciplines (including economists, spatial analysts, agronomists and hydrologists) and scales (paddock to regional). The model examines the trade-offs between agricultural productivity and Basin Plan obligations in the context of water use efficiency targets, future shocks to the resource base and access to groundwater. Importantly, the model predictions explicitly account for imperfect knowledge and uncertainty.

This paper describes the main elements of the bio-economic model and aims to demonstrate the utility of the model to better inform water management and irrigated agriculture policy.

\section{NORTHERN VICTORIA IRRIGATION ZONES}

The study region considers all major irrigation districts within northern Victoria. A total of thirty six (36) irrigation regions are modelled (Figure 1). Each modelled region is based on the spatial intersection of irrigation districts, river systems, water trading zones and SDL reporting regions (surface water and groundwater).

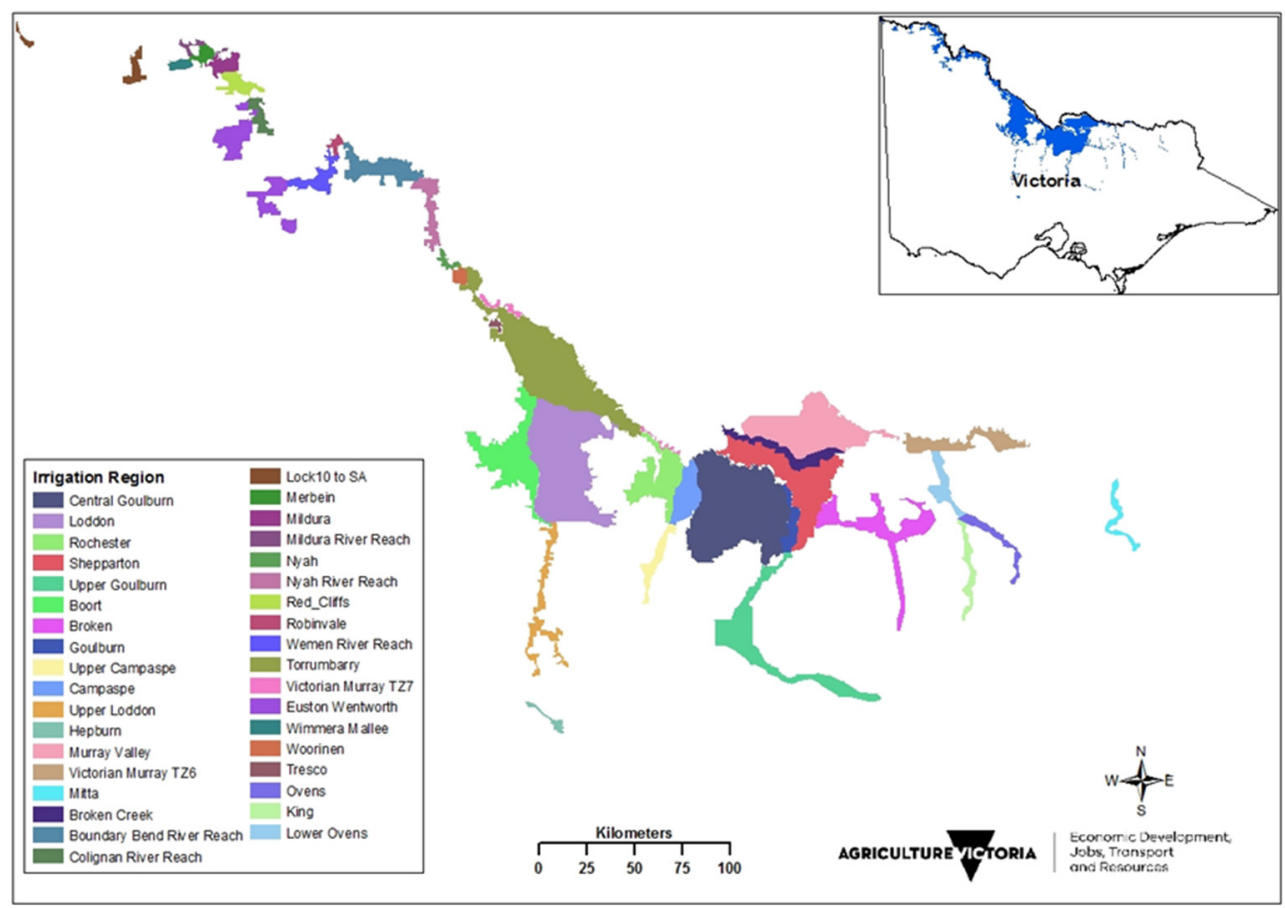

Figure 1. Modelled irrigation regions. 
Beverly et al., Optimising irrigated agricultural productivity under varying water availability: industry challenges in northern Victoria

\section{BIO-ECONOMIC MODELLING}

\subsection{Overview}

The Water Policy Model (WPM) was developed to estimate water demands in irrigation areas and determine efficient water allocations per region. The recent emphasis on ensuring sustainable water use by reducing extraction levels has increased the importance of identifying economically efficient allocations of water. Bio-economic models, such as the WPM, can be used to evaluate the economic efficiency implications of specific water allocations and water allocation methods (such as water trading) to ensure that environmental goals are achieved at lowest economic cost.

The range of farm activities modelled includes permanent horticulture, summer and winter crops, livestock production, hay production for on-farm use or sale, and maintaining and feeding pasture. The commodities considered are irrigated and dryland pastures, winter grains, summer grains, pome fruits, grapes, tomatoes, citrus, stone fruits, almonds, olives, dairy cattle, beef cattle and sheep. The total irrigated area modelled is $1,601,474$ ha.

The WPM was designed to consider policy impacts in the Victorian part of the Murray-Darling Basin and to identify opportunities to mitigate declines in water availability in that region at least cost. Region-wide reductions in water availability would typically cause a shift of resources from irrigated agricultural activities to dryland activities and a reduction in irrigated agricultural output. The WPM aims to predict such shifts and uses a spatial equilibrium approach in which a solution of the model determines the area of land within various agricultural enterprises and volumes of water bought and sold in each region.

Key features include:

- A non-linear production function, based on O’Connell (2011), applied to all horticultural crops describing the relationship between applied water and crop yield, and allowing for crop maintenance by way of minimum water application;

- Groundwater pumping (as a supplementary and/or alternative water resource); and

- Variable water price based on seasonal allocation.

\subsection{Datasets}

\subsubsection{Land use}

Land use information incorporated in the WPM model was sourced from various data sets. The default designation of land use and extent was sourced from Australian Land Use Mapping (ALUM) (http://adl.brs.gov.au) and to a lesser degree the Victorian Land Use Information System (VLUIS) (www.data.vic.gov.au/data/dataset/victorian-land-use-information-system-2014-2015). This composite data was augmented with Landsat 8 remotely sensed spatial data. The resolution of the Landsat 8 spatial mapping was $30 \mathrm{~m} \times 30 \mathrm{~m}$. In the case of the Sunraysia district, baseline land use was derived from survey and benchmark information (SunRISE Mapping and Research: Crop2014_NorthWestVIC.shp), whereas SPC survey data was used to define baseline land use in the Goulburn Valley.

\subsubsection{Economic value of dairy, mixed cropping and horticulture enterprises}

The economic value of key inputs and profits for dairy and mixed cropping systems was based on published data. Indicative data on commodity prices, variable costs, water tariffs, and overhead costs were obtained from a range of on-line sources, as reported in Stott and Beverly (2017). Estimates of gross margins, EBIT (or operating profit) and annualised capital costs for irrigated horticultural enterprises were based on benchmark data and expert knowledge.

\subsubsection{Economic value of surface water and groundwater}

Surface water is valued using the unit cost of purchasing or selling water in the temporary (allocation) market as outlined by Stott (2014). A measure of the seasonal surface water price and allocations was developed for the combined Goulburn and Murray River basin systems. This relationship was based on a linear functional form fitted to mid-February announced high reliability water allocations and the natural logarithm of allocation water price data over the 5-year period commencing $1^{\text {st }}$ July 2007 . Based on the above relationship, Stott (2014) concluded that the economic value of surface water to farmers varies with the quantity of water allocated. The lower the allocation, the higher the value, with the increase in price (\$/ML) rising exponentially. 
Beverly et al., Optimising irrigated agricultural productivity under varying water availability: industry challenges in northern Victoria

The economic value of groundwater was based on Stott (2014), which used partial net cash flow budgeting to quantify the equal annual pumping costs (EAC) for shallow and deep bores across northern Victorian. An average economic value for groundwater of $\$ 110 / \mathrm{ML} / \mathrm{yr}$ was used in the analysis.

\subsubsection{Available groundwater}

Groundwater pumping data was based on the 2006-2007 groundwater usage estimates as reported in Victorian State Water Accounts (/http://waterregister.vic.gov.au/water-availability-and-use/victorian-wateraccounts). This period was selected as it represented peak usage during drought conditions. Groundwater bore data, including screen depths and aquifer penetrated, was sourced from the Northern Victoria Groundwater Model (Beverly and Hocking, 2014). This information was used to estimate the groundwater extractions from each groundwater SDL region within each modelled irrigation district. Available groundwater was assumed to be the difference between SDL and 2006-2007 usage such that the sum of available groundwater and peak historical usage does not exceed SDL settings.

\subsubsection{Water use}

Water use estimates were based on a combination of published data, satellite imagery and application of a biophysical, phenologically-based horticulture model. Interpretation of crop water requirement based on satellite image analysis provided estimates of the distribution and water usage across individual irrigation zones. These distributions of surface water use were also used in the uncertainty analysis.

\subsection{Optimisation model}

The design of the optimisation model is to maximise total net benefits expressed as the difference between producer profit and costs for a given water availability target/s with the construct of the model being based on Doole (2015).

The study region comprises individual irrigation regions denoted $r$, where $r=[1,2, \ldots, R]$ and $R$ is the total number of irrigation regions in northern Victoria. Each irrigation region is spatially defined based on SDL reporting requirements, channel network and trading rule considerations. Within each irrigation region varying land uses exist. The area assigned to a land use is denoted $l_{s}$ where $l_{s}=\left[1,2, . ., L_{s}\right]$ and $L_{s}$ is the total number of land uses in irrigation region $r$. Notably the total number of land uses within each irrigation region is variable. Within a given land use, various farm management systems can exist. In this study horticultural enterprises were differentiated based on market (fresh or tinned) whereas mixed cropping and dairy systems were differentiated based on land use mapping. The index of each farm management system for a land use in each irrigation region is denoted $m_{r, l}$ where $m_{r, l}=\left[1,2, \ldots, M_{r, l}\right]$ and $M_{r, l}$ is the total number of systems for land use $l$ in irrigation region $r$.

The objective of the optimisation is to maximise net profit in each region $n$ comprised of $r$ irrigation zones as defined by equation 1 . Two decision variables describe the net profit. First, the area (ha) allocated to each management practice $m$ in land use $l$ and irrigation zone $r$ as denoted by $A_{r, l, m}$. The associated net profit is denoted by $J_{r, l, m}\left(\$ \mathrm{ha}^{-1}\right)$. Second, the cost of groundwater pumping in each irrigation zone is defined by $\operatorname{cgwp}_{\mathrm{r}, \mathrm{p}}\left(\$ \mathrm{ML}^{-1}\right)$. The key groundwater decision variable is the volume of groundwater extraction in each irrigation region where $p=[1,2, \ldots P]$ and $P$ is the total number of SDL groundwater zones in irrigation region $r$. Total net profit in each region $n\left(\pi^{n}\right)$ is computed as:

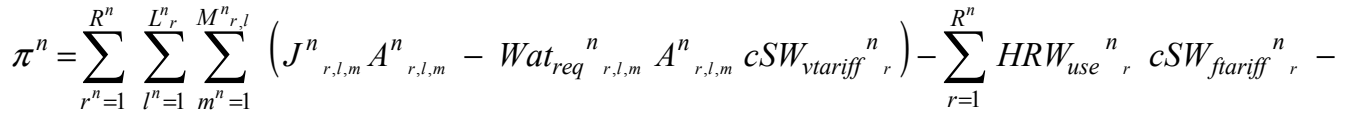

$$
\begin{aligned}
& \sum_{r^{n}=1}^{R^{n}} c S W_{\text {buy }}{ }^{n}{ }_{r} S W_{\text {buy }}{ }^{n}{ }_{r}+\sum_{r^{n}=1}^{R^{n}{ }_{r}} c S W_{\text {sell }{ }_{r}{ }_{r}} S W_{\text {sell }{ }_{r}{ }_{r}}-\sum_{r^{n}=1}^{R^{n}} \sum_{p^{n}=1}^{P^{n}{ }_{r}} c G W p m p^{n}{ }_{r, p} G W_{r, p}^{n}
\end{aligned}
$$

where Wat $_{\text {req }}$ is the crop water requirement, $c S W_{\text {vtariff }}$ is the variable water tariff (cost of irrigation water delivered), $H R W_{\text {use }}$ is the high reliability water use, $c S W_{\text {ftariff }}$ is the fixed water tariff (fixed tariff for the high reliability water entitlement owned), $c S W_{b u y}$ is the purchase price of water (transaction costs of importing water allocations), $S W_{b u y}$ is the volume of water bought, $c S W_{\text {sell }}$ is the cost of water sold (cost of exporting water allocations), $S W_{\text {sell }}$ is the volume of water sold, $c G W_{\text {pump }}$ is the cost of groundwater pumping and $G W$ is the volume of groundwater pumped. 
Beverly et al., Optimising irrigated agricultural productivity under varying water availability: industry challenges in northern Victoria

Total net benefit in the context of this model represents total gross margin and is defined as gross agricultural income less the variable costs incurred in production. It is therefore a measure of the profitability of agriculture and can be used to gauge the impact on the irrigation sector of changed water availability. The revenues and costs associated with each farm management system for a land use in each irrigation region are calculated respectively as:

$$
\begin{aligned}
& \text { revenue }^{n}=\sum_{r^{n}=1}^{R^{n}} \sum_{l^{n}=1}^{L_{r}^{n}} \sum_{m^{n}=1}^{M^{n} r_{r, l}} x_{r, l, m}^{n} q_{r, l, m}^{n} p_{r, l, m}^{n} \\
& \operatorname{cost}^{n}=\sum_{r^{n}=1}^{R^{n}} \sum_{l^{n}=1}^{L^{n}} \sum_{m^{n}=1}^{M^{n} r_{r, l}} x_{r, l, m}^{n} a_{r, l, m}^{n} c_{r, l, m}^{n}
\end{aligned}
$$

where $x$ is the magnitude of activity (e.g. pastures, crops, livestock), $q$ denotes the quantity of product produced per unit of activity, $p$ is the per-unit price of each product, $a$ is the amount of resource required perunit activity and $c$ is the per-unit cost of resource. Model constraints include available area, available water, trading rules and suitable agricultural enterprise.

The model adopts an annual time frame but represents a 20 year medium term outlook. This means that the model optimises the weighted average of the net economic returns associated with each state of nature. The bio-economic model components were solved using nonlinear programming with the CONOPT solver in the General Algebraic Modelling System (GAMS) (Brooke et al., 2008).

\subsection{Uncertainty analysis}

Sensitivity analysis identified key inputs that most impacted on model predictions. For this study, six sensitive inputs were selected, namely: (1) seasonal water allocation; (2) cost of irrigation water delivered imposed as a variable tariff per ML; (3) water use efficiency; (4) sale price of heifers; (5) purchase price of grain; and (6) seasonal allocation of groundwater in excess of SDL requirements. Each input was assigned either a normal or uniform distribution from which Latin HyperCube Sampling was performed to derive a range of likely model prediction outcomes. The normal distribution attributed to water use efficiency was based on analysis of satellite derived data.

\subsection{Scenarios}

This paper will focus on four scenarios only, namely:

1. Current ideal case: This represents the most economically efficient allocation of water and land use configuration. The land use within each irrigation region is constrained to current enterprises. That is, the mix of horticultural systems within each irrigation zone is constrained to existing land uses.

2. Improved water yield efficiency case: This scenario applies the same assumptions as the current ideal case with an aspirational 10\% improvement in water efficiency via genetic improvement, system design and precision water management.

3. Groundwater case: This scenario applies the same assumptions as the current ideal case with access to $50 \%$ of available groundwater (as defined above). This target is conservative in recognition of groundwater/surface water connectivity, water quality, aquifer yield and bore interference issues.

4. Combined case: This scenario is a combination of all the above scenarios.

\section{RESULTS}

The annualised results for each scenario considered are summarised in Table 1. These results are optimal and assume widespread adoption of the proposed intervention and/or practice change.

Improvements in water yield efficiency (scenario 2) are shown to significantly increase gross margins by $\$ 610 \mathrm{~m}$ relative to scenario 1 . This scenario also highlights that water yield improvements have limited impact on total water use but enable an expansion of irrigated area by 49,167 ha within the existing irrigation zone footprint.

Utilisation of additional groundwater (scenario 3) resulted in a 271 GL reduction in surface water use. The reduction in surface water use was substituted by groundwater; the total water use remained unchanged. 
Beverly et al., Optimising irrigated agricultural productivity under varying water availability: industry challenges in northern Victoria

Gross margins are marginally increased by $\$ 145 \mathrm{~m}$ relative to scenario 1 whereas gross income has increased from $\$ 5.91 \mathrm{~b}$ to $\$ 6.11 \mathrm{~b}$.

A combination of improvements in water efficiency and access to available groundwater (scenario 4) increases gross margins by $\$ 775 \mathrm{~m}$ relative to scenario 1 whereas gross income has increased from $\$ 5.91 \mathrm{~b}$ to $\$ 7.08$ b. Irrigated area has increased by $70 \%$ from the current ideal condition, with much of this increase due to an expansion in mixed cropping of $250,767 \mathrm{ha}$; available land constraints restrict expansion in dairy and horticulture.

The results from the uncertainty analysis for gross margins and water use by horticulture are summarised in Figures 2 and 3 respectively. Figure 3 also includes scenarios 3 and 4 groundwater (Scen3GW and Scen4-GW) derived usage. Results suggest that improved water use efficiency (scenario 2) increases the median gross margin value by

Table 1. Potential impact (optimal) assuming 100\% adoption of various water availability scenarios

\begin{tabular}{|l|l|c|c|c|c|}
\hline Scenario & Variable & Dairy & $\begin{array}{l}\text { Mixed } \\
\text { cropping }\end{array}$ & Hort. & Total \\
\hline 1. Current ideal & Irrigated area (ha) & 42,297 & 221,487 & 94,353 & 358,137 \\
\hline & Water use (ML) & 207,488 & 296,793 & 640,245 & $1,144,526$ \\
\hline & Gross margin (\$m) & 393 & 450 & 2,781 & 3,624 \\
\hline 2. Improved WUE & Irrigated area (ha) & 40,802 & 270,371 & 96,131 & 407,304 \\
\hline & Water use (ML) & 189,999 & 362,297 & 592,230 & $1,144,526$ \\
\hline & Gross margin (\$m) & 400 & 567 & 3,267 & 4,234 \\
\hline 3. With Groundwater & Irrigated area (ha) & 42,297 & 423,371 & 94,353 & 560,021 \\
\hline & Water use (ML) & 176,628 & 405,265 & 562,633 & $1,144,526$ \\
\hline & Gross margin (\$m) & 392 & 602 & 2,776 & 3,770 \\
\hline 4. Combined & Irrigated area (ha) & 40,802 & 472,254 & 96,132 & 609,188 \\
\hline & Water use (ML) & 136,322 & 492,657 & 515,547 & $1,144,526$ \\
\hline & Gross margin (\$m) & 396 & 741 & 3,262 & 4,399 \\
\hline
\end{tabular}
$\$ 757 \mathrm{~m}$ and reduces

the variability relative to scenario 1 . Similarly, access to groundwater (scenarios 3 and 4 ) is shown to reduce the variability and increase the median gross margin value. The increase in median gross margin due to access to groundwater (scenario 3) is $\$ 395 \mathrm{~m}$ relative to scenario 1 which is less than the increased profitability due to improvement in water efficiency (scenario 2). However, under the combined case (scenario 4) the increase in median gross margin relative to scenario 1 is significantly greater at $\$ 1.2 \mathrm{~b}$. With regard to irrigated horticulture (Figure 3), results infer that improved water use efficiency increases water utilisation and hence gross margins. In all cases, access to groundwater reduces the variability in water use when compared to the current ideal case. Relative to scenario 1, water use by horticulture increased on average by 94 GL, 34 GL and 170 GL for scenarios 2, 3 and 4 respectively. On average, 33\% of additional groundwater is utilised by horticulture, $24 \%$ by dairy and $43 \%$ by mixed cropping.

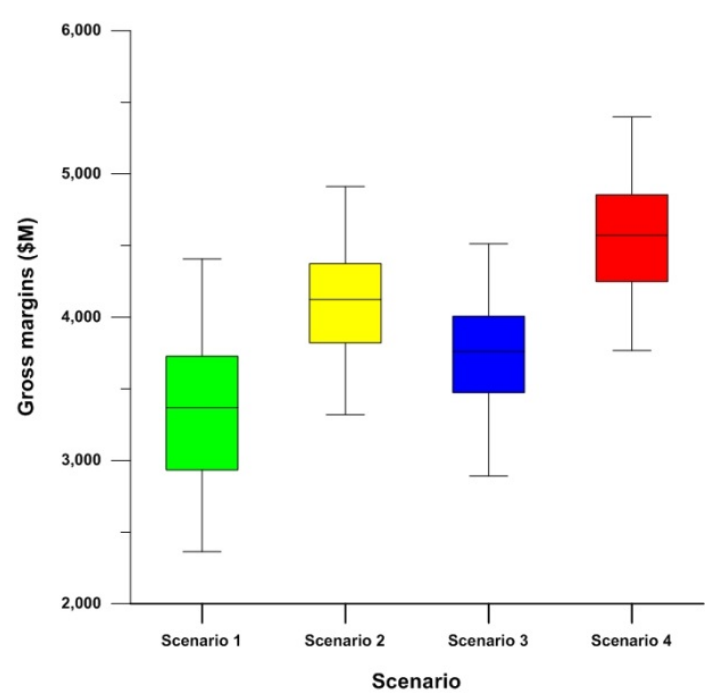

Figure 2. Predicted gross margins $(\$ \mathrm{~m})$ for each scenario considered based on assigned parameter distributions.

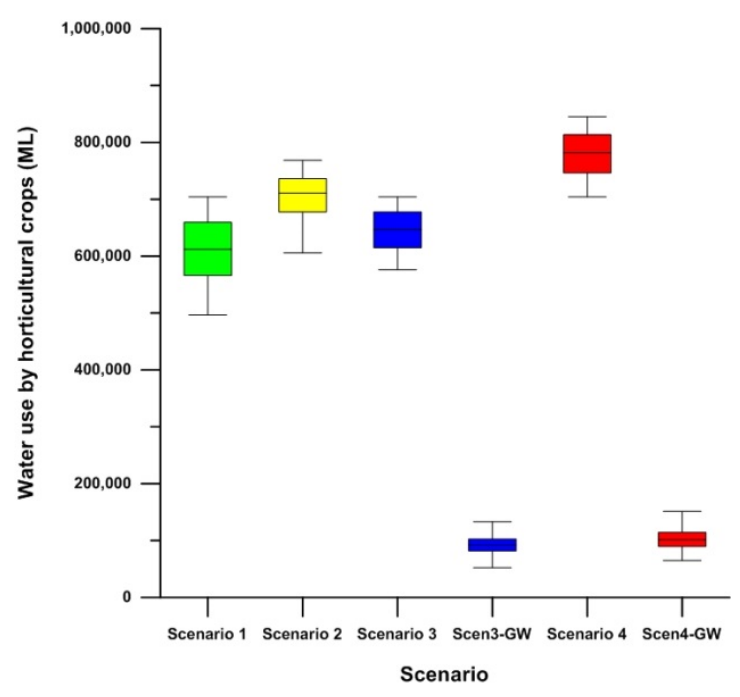

Figure 3. Water use (ML) for horticulture under each scenario 
Beverly et al., Optimising irrigated agricultural productivity under varying water availability: industry challenges in northern Victoria

\section{DISCUSSION AND CONCLUSIONS}

Results from this study concluded that maximising agricultural profitability, whilst achieving environmental flow obligations, will require careful targeting of agricultural practices and a possible review of water trade policy. A combination of improved water efficiency, via genetic improvement, system design and precision water management, coupled with access to $50 \%$ of available groundwater provides the greatest potential to maximise irrigated agricultural gross margins to $\$ 4.4 \mathrm{~b}$ (or gross income of $\$ 7.1 \mathrm{~b}$ ) relative to current ideal maximum gross margins of $\$ 3.6 \mathrm{~b}$ (or gross income of $\$ 5.9 \mathrm{~b}$ ). The presented results have constrained land use mix and land area to current conditions. Were these constraints to be relaxed, then alternative options are available to further maximise agricultural profitability.

This paper demonstrates that the model takes appropriate account of the heterogeneity of farming systems and their respective abilities to respond tactically and strategically to changing water supplies. This application integrated numerous physical and economic data sets and biophysical model results. The developed framework is shown to have a demonstrated capacity to test: (1) the impacts of alternative agricultural systems; (2) the optimal likely impact from increased water use efficiencies; and (3) the economic impacts of surface water and groundwater substitution. To this end, the bio-economic framework has provided enhanced regional scale economic modelling enabling the development of a more robust policy framework than previously possible.

\section{ACKNOWLEDGEMENTS}

The authors acknowledge the contribution of Anna Weeks for the provision of satellite derived data and Rukman Wimalasuriya for providing background material related to whole-farm models of farming systems in Victoria. This project was funded by the State of Victoria.

\section{REFERENCES}

Bharati, L., Rodgers, C., Erdenberger, T., Plotnikova, M., Shumilov, S., Vlek, P. and Martin, N. (2008). Integration of economic and hydrologic models: exploring conjunctive irrigation water use strategies in the Volta Basin, Agricultural Water Management, 95, 925-936. doi:10.1016/J.AGWAT.2008.03.009

Beverly, C., Roberts, A., Doole, G., Park, G. and Bennett, F.R. (2016). Assessing the net benefits of achieving water quality targets using a bio-economic model, Environmental Modelling and Software, pp. 229-245. doi. 10.1016/j.envsoft.2016.08.012.

Beverly, C. and Hocking, M. (2014). DEPI Northern Victoria Groundwater Model Conceptualisation and Calibration, Victorian Department of Primary Industries, Rutherglen, pp150.

Brooke, A., Kendrick, D., Meeraus, A. and Raman, R. (2008). GAMS-A user's Guide. GAMS Development Corporation, Washington, DC

Doole, G.J. (2015). A flexible framework for environmental policy assessment at the catchment level, Computers and Electronics in Agriculture, 114, pp. 221-230

Murray-Darling Basin Authority (2012). Water Act 2007: Basin Plan, Commonwealth of Australia, Canberra.

O’Connell, M. (2011). Satellite Based Yield - Water Use Relationships of Perennial Horticultural Crops. A thesis submitted in total fulfilment of the requirements of the degree of Doctor of Philosophy. Department of Agriculture and Food Systems, Melbourne School of Land and Environment, The University of Melbourne, Victoria, Australia.

Stott, K. (2014). The economic impact of groundwater SDLs on irrigated agriculture in the northern Victorian MDB. Agriculture Research Technical Report, Victorian Department of Environment and Primary Industries, Carlton.

Stott, K. and Beverly, C. (2017). Bio-economic impacts to industry from changing water allocations. Agriculture Research Milestone Report No.3, A technical report detailing the development of representative farm economic models for each major irrigated industry in Northern Victoria, Victorian Department of Environment and Primary Industries, Carlton.

Warfe, D.M., and Tisdell, J.G. (2016). A bioeconomic analysis of conserving freshwater values in an agricultural landscape, Marine and Freshwater Research, http://dx.doi.org/10.1071/MF15132. 